\title{
Prevalence of Risk Factors of Coronary Artery Disease above 30 Years of Age in an Urban Setting
}

\author{
Ratan Prakash Dhir ${ }^{1}$, Harivansh Chopra ${ }^{2}$, Tanveer Bano ${ }^{3}$, Seema Jain ${ }^{4}$, \\ Ganesh Singh $^{5}$, Rajiv Nehra ${ }^{6}$ \\ ${ }^{I}$ (Tutor, Department Of Community Medicine, L.L.R.M. Medical College, Meerut, U.P., India) \\ ${ }^{2,3,4}$ (Professor, Department Of Community Medicine, L.L.R.M. Medical College, Meerut, U.P., India) \\ ${ }_{5}^{5}$ (Associate Professor, Department Of Community Medicine, L.L.R.M. Medical College, Meerut, U.P., India) \\ ${ }^{6}$ (Department Of Biochemistry, L.L.R.M. Medical College, Meerut, U.P., India)
}

\begin{abstract}
The prevalence of coronary artery disease is dependent upon the presence of multiple risk factors. These risk factors specially the modifiable one, can be brought under control by life style modifications. World health organization has recommended a STEPs approach for the assessment of risk factors of coronary artery disease. It has two component, core and expanded. Objectives: There is paucity of data as far as expanded assessment is concerned. The present study was conducted with the objective to find out the prevalence of risk factors of coronary artery disease using WHO standardised STEPs approach including investigations specially fasting blood sugar and total cholesterol. Materials and Methods: The sample size was calculated by using the formula $n=Z^{2} p q / d^{2}$. For a two sided at $95 \%$ confidence interval, the value of $Z_{\alpha / 2}=1.96, p$ is prevalence, $q=1$ $-p$ and $d$ is relative precision. In present study the prevalence of hypertension was taken as $40 \%$ with $10 \%$ relative precision. The sample size came out to be 576. Results: Amongst modifiable risk factors, the high salt intake was found to be highest in $48.6 \%$ subjects followed by hypertension in $44.4 \%$ subjects. $25.2 \%$ subjects were having raised blood sugar. $37.7 \%$ were pre-obese while only $16.8 \%$ were obese. Only $5.4 \%$ subjects were having hypercholesterolemia as per WHO cut-off.
\end{abstract}

Keywords: CHD, NCD, NPCDCS, STEPS, WHO,

\section{Introduction}

Coronary heart disease (CHD) is an impairment of heart function due to inadequate blood flow to the heart compared to its needs, caused by obstructive changes in the coronary circulation to the heart. ${ }^{1}$ There have been a sharp increase in the number of deaths due to cardiovascular diseases in the last two decades, in 1990 there were an estimated 50 million deaths globally and approximately 14 million (28\%) were due to cardiovascular diseases, ${ }^{2}$ which rose to 38 million deaths in 2012 and it is predicted that by 2030 CVD will be responsible for 52 million deaths alone. Approximately $42 \%$ of all NCDs deaths globally occurred before the age of 70 years; $48 \%$ of NCD deaths in low- and middle-income countries and $28 \%$ in high-income countries were individuals aged under 70 years. $^{3}$

In India, cardiovascular disease (CVD) accounts for 53.5\% of NCD mortality, and cardiovascular risk factors, which were initially confined to more affluent strata with inappropriate diet and lack of physical activity, are becoming more common among middle and lower socioeconomic strata of Indian urban and rural populations. ${ }^{4,5}$

WHO has predicted that from year 2000 to 2020 DALYs lost from CHD in India shall double in both men and women from the current 7.7 and 5.5 million respectively. ${ }^{6}$

The World Health Organization (WHO) has developed STEP wise Surveillance (STEPS) approach of Risk Factors as a part of global surveillance strategy in response to the growing need for country-level trends in noncommunicable diseases. By using the same standardized questions and protocols, all countries can use STEPS information not only for monitoring within-country trends but also for making between-country comparisons. There is paucity of data in urban Meerut as far as CHD risk factors is concerned. The present study was conducted with the objective to find out the prevalence of risk factors of coronary artery disease using WHO standardised STEPs approach, in which in STEP 3 only core investigations fasting blood sugar and total cholesterol were taken.

\section{Materials And Methods}

There were 80 wards in Meerut, one ward was selected randomly, which came out to be ward 45 . Ward 45 voter list was procured from Nagar Nigam. The sample size was calculated by using the formula $n=Z^{2} p q / d^{2}$. For a two sided at $95 \%$ confidence interval, the value of $Z_{\alpha / 2}=1.96, p$ is prevalence, $q=1-p$ and $d$ is relative precision. In present study the prevalence of hypertension was taken as $40 \%$ with $10 \%$ relative precision. The 
sample size came out to be 576 . Total individuals of age 30 years and above were found to be 8346 . To derive the sampling interval 8346 was divided by 576 and then resultant was 14 . Then a random number less than 14 was selected which came out to be 10 , then every $14^{\text {th }}$ individual were choose to complete the sample size of 576.

\section{Results}

Table 1 is showing socio-demographic distribution of study participants.

\begin{tabular}{|c|c|c|c|}
\hline \multicolumn{2}{|l|}{ Variable } & \multirow{2}{*}{$\begin{array}{c}\text { Total }(n=576) \\
104\end{array}$} & \multirow{2}{*}{$\begin{array}{c}\text { Percentage }(\%) \\
18.1 \%\end{array}$} \\
\hline \multirow{5}{*}{ Age } & $30-39$ years & & \\
\hline & $40-49$ years & 180 & $31.3 \%$ \\
\hline & $50-59$ years & 127 & $22.0 \%$ \\
\hline & $60-69$ years & 110 & $19.1 \%$ \\
\hline & $\geq 70$ years & 55 & $9.5 \%$ \\
\hline \multirow{2}{*}{ Sex } & Male & 245 & $42.5 \%$ \\
\hline & Female & 331 & $57.5 \%$ \\
\hline \multirow{3}{*}{ Caste } & General & 309 & $53.7 \%$ \\
\hline & $\mathrm{OBC}$ & 120 & $20.8 \%$ \\
\hline & $\mathrm{SC}$ & 147 & $25.5 \%$ \\
\hline \multirow{2}{*}{ Marital status } & Married & 565 & $98.1 \%$ \\
\hline & Un-married & 11 & $1.9 \%$ \\
\hline \multirow{2}{*}{ Type of family } & Nuclear & 370 & $64.2 \%$ \\
\hline & Joint & 206 & $35.8 \%$ \\
\hline \multirow{5}{*}{ Socio-economic status } & Upper class (I) & 01 & $0.2 \%$ \\
\hline & Upper middle class (II) & 45 & $7.8 \%$ \\
\hline & Lower middle class (III) & 234 & $40.6 \%$ \\
\hline & Upper lower class (IV) & 252 & $43.8 \%$ \\
\hline & Lower class $(\mathrm{V})$ & 44 & $7.6 \%$ \\
\hline
\end{tabular}

Table no. 1 is showing the demographic profile of the study population. The maximum number of participants were found in $40-49$ years of age (31.3\%)followed by $22.0 \%$ in $50-59$ years while the minimum participants $9.5 \%$ were found 70 years and above age group. Among 576 population, $57.5 \%$ were found to be females and $42.5 \%$ were male. Caste wise $53.7 \%, 25.5 \%$ and $20.8 \%$ were General, SC and OBC respectively. Majority of population $98.1 \%$ were married while only $1.9 \%$ were unmarried. Nuclear family was found to be more $(64.2 \%)$ than joint family $(35.8 \%)$. According to modified Kuppuswamy socio-economic scale $0.2 \%$, $7.8 \%, 40.6 \%, 43.8 \%$ and $7.6 \%$ were belongs to upper class (I), upper middle class (II), lower middleclass (III), upper lower class (IV) and lower class (V) respectively.

Table 2: Prevalence of life style risk factors among study population

\begin{tabular}{|l|c|c|c|c|}
\hline \multirow{2}{*}{ Risk Factors } & \multicolumn{4}{|c|}{ Potal study population $(\mathrm{n}=576)$} \\
\cline { 2 - 5 } & MALE & FEMALE & TOTAL & \\
\hline Alcohol intake & $67(27.4 \%)$ & $00(0.0 \%)$ & $\begin{array}{c}67 \\
(11.6 \%)\end{array}$ & $\chi 2=99.8, \mathrm{df} 1, \mathrm{p}=0.0001$ \\
\hline High salt intake & $114(46.5 \%)$ & $\begin{array}{c}166 \\
(50.2 \%)\end{array}$ & $\begin{array}{c}280 \\
(48.6 \%)\end{array}$ & $\chi 2=0.74, \mathrm{df} 1, \mathrm{p}=0.39$ \\
\hline $\begin{array}{l}\text { Moderate intensity } \\
\text { activity for }>10 \text { min. }\end{array}$ & $200(81.6 \%)$ & $\begin{array}{c}280 \\
(84.6 \%)\end{array}$ & $\begin{array}{c}480 \\
(83.3 \%)\end{array}$ & $\chi 2=0.88, \mathrm{df} 1, \mathrm{p}=0.35$ \\
\hline Smoking & $58(23.7 \%)$ & $03(0.9 \%)$ & $\begin{array}{c}61 \\
(10.6 \%)\end{array}$ & $\chi 2=77.1, \mathrm{df} 1, \mathrm{p}=0.000$ \\
\hline
\end{tabular}

Prevalence of alcohol intake among males was $11.6 \%$ while none of females have been found alcoholic which was found to be statistically significant $(\mathrm{p}<0.05)$ with Yate's correction. The prevalence of high salt intake was $48.6 \%$ in this study. Table 32 shows the history of high salt intake was found more in females $(50.2 \%)$ than the males $(46.5 \%)$ but this gender wise difference was not found to be significant $(\mathrm{p}>0.05) .84 .6 \%$ females and $81.6 \%$ male were found to be physically active respectively and this difference was not found to be significant $(\mathrm{p}>0.05)$. Overall prevalence of smoking was significantly higher among males (23.7\%), only 3 $(0.9 \%)$ females reported to suffer of smoking addiction. The difference of smoking in relation to gender was found to be significant $(\mathrm{p}<0.05)$. 
Table 3: Prevalence of physical and biochemical risk factors among study population

\begin{tabular}{|c|c|c|c|c|}
\hline \multirow[t]{2}{*}{ Risk Factors } & \multicolumn{4}{|c|}{$\begin{array}{c}\text { Prevalence } \\
\text { Total study population }(n=576)\end{array}$} \\
\hline & MALE & FEMALE & TOTAL & \\
\hline High blood pressure & $118(48.2 \%)$ & $138(41.7 \%)$ & $256(44.4 \%)$ & $\chi^{2}=2.39$, df $1, p=0.12$ \\
\hline High blood sugar & $73(29.8 \%)$ & $72(21.8 \%)$ & $145(25.2 \%)$ & $\chi^{2}=4.84$, df $1, p=0.02$ \\
\hline Hypercholesterolemia & $13(5.3 \%)$ & $18(5.5 \%)$ & $31(5.4 \%)$ & $\chi^{2}=0.48$, df $1, p=0.94$ \\
\hline $\begin{array}{c}\text { Nutritional status } \\
>\text { Pre-obese } \\
>\text { Obese }\end{array}$ & $\begin{array}{l}96(39.2 \%) \\
42(17.1 \%)\end{array}$ & $\begin{array}{l}121(36.6 \%) \\
55(16.6 \%)\end{array}$ & $\begin{array}{r}217(37.7 \%) \\
97(16.8 \%)\end{array}$ & $\begin{array}{l}\chi^{2}=0.56, \text { df } 1, p=0.45 \\
\chi^{2}=0.17, \text { df } 1, p=0.67\end{array}$ \\
\hline
\end{tabular}

As shown in table 3, amongst modifiable risk factors, hypertension was found to be highest in $44.4 \%$ subjects. Among all the subjects pre-obese, raised blood sugar and obesity were found to be $37.7 \%, 25.2 \%$ and $16.8 \%$ subjects respectively. Only 5.4\% subjects were having hypercholesterolemia as per WHO cut-off.

\section{Discussion}

In the present study the prevalence of hypertension in males was $48.2 \%$ and in females $41.7 \%$. Low prevalence was reported by, Parikh S. et al $^{7}$ in Ahmedabad city which was $37 \%$ in males and $36 \%$ in females. Garg A. et al $^{8}$ reporting $33.7 \%$ males and $31.5 \%$ females were hypertensive while Sekhri T. et al ${ }^{9}$ reported that $22.4 \%$ of males and $13.4 \%$ of females were hypertensive.

The overall prevalence of high blood sugar level was found $25.2 \%$ which is similar to study done by Singh $\mathrm{A}$ et al ${ }^{10}$ which is $23.2 \%$. In the present study the prevalence of high blood sugar was $29.8 \%$ and $21.8 \%$ in males and females respectively and the difference was also found to be statistically significant. Lower prevalence of diabetes was reported by Reddy K.S. et al ${ }^{11}$ which was $11.2 \%$ in males and $8.2 \%$ in females, Parikh S. et $\mathrm{al}^{7}$ who reported $9.7 \%$ males and $10.9 \%$ in females and Garg A. et $\mathrm{al}^{8}$ who reported that it which was $15.7 \%$ in males and $19.8 \%$ in females.

In the present study the prevalence of hypercholesterolemia as per cut-off value of WHO was $5.3 \%$ in males and $5.5 \%$ in females. High prevalence was reported by Gupta R. et al ${ }^{12}$ in Jaipur 33\% in males and $32.7 \%$ in females, Garg A. et $\mathrm{al}^{8}$ also reported the prevalence of hypercholesterolemia $30.3 \%$ in males and $36.9 \%$ in females and other ${ }^{9,13,14}$ also reported similar findings.

The overall prevalence of obesity was $56.3 \%$ in males and $53.2 \%$ in females. The findings of present study were supported by, Mohan V. et al ${ }^{15}$ reported $36.5 \%$ males and $52 \%$ females were obese, whereas Prabhakaran D.et $\mathrm{al}^{14}$ reported prevalence of obesity among males $(35 \%)$ only. High prevalence were reported by, Garg A. et $\mathrm{al}^{8}$ reported obesity in $46 \%$ males and $61 \%$ females, Reddy K.S. et al ${ }^{11}$ reported that $50.9 \%$ males and $51.9 \%$ females were obese. Low prevalence were reported by, Gupta R. et al ${ }^{13}$ reported obesity in $8.3 \%$ of males and $15.8 \%$ of females, Gupta R.et al $^{12}$ andSekhri T. et al ${ }^{9}$ also reported low prevalence in male and female participants.

In present study, statistically significant association was found between alcohol use and sex and the prevalence of current/ever drinkers was $27.3 \%$ in males and $0 \%$ in females. Garg A. et al ${ }^{8}$ reported $55 \%$ males and $2.7 \%$ females were current drinkers and Sugathan T.N. et al ${ }^{16}$ reported $51 \%$ males and $0.9 \%$ females were current/ever users. Lower prevalence of alcohol use were reported by, Mohan V. et al ${ }^{15}$ reported $30.2 \%$ males and $0 \%$ females were ever drinkers and Gupta R.et al $^{13}$ reported $13.1 \%$ males and $0 \%$ females were ever drinkers. High prevalence was reported by Mishra P.J. et al ${ }^{17}, 81.6 \%$ males and $49.7 \%$ females were current users of alcohol.

In our study, subjects with their work involvement of moderate physical activity for more than 10 minute was reported in $84.6 \%$ of females in comparison of $81.6 \%$ of males. A lower prevalence was also reported by, Gupta R. et al ${ }^{13}$ among $53.9 \%$ of females and $61.2 \%$ of males were physically active, supported by Sugathan T. et $\mathrm{al}^{16}$ and Aroor B. et $\mathrm{al}^{18}$. The overall prevalence of physical activity in our study was $83.3 \%$.

In present study, the prevalence of ever smoker was $23.7 \%$ in males but $0.3 \%$ among the females. Similar results were observed by, Mohan V. et al $^{15}$ reported $56.3 \%$ males and $0.5 \%$ females were ever smokers. Low prevalence were observed by, Garg A. et al ${ }^{8}$ reported $32.6 \%$ in males and $4.5 \%$ in females, Gupta R. et $\mathrm{al}^{13}$, Gupta et $\mathrm{al}^{11}$, Reddy K.S. et $\mathrm{al}^{11}$, Sekhri T. et $\mathrm{al}^{9}$, Aroor B. et $\mathrm{al}^{18}$ and Mishra P.J. et $\mathrm{al}^{17}$ all reported low prevalence. Higher prevalence was reported by, Sugathan T. et $\mathrm{al}^{16}$. Prabhakaran D. et $\mathrm{al}^{14}$.

\section{Conclusion}

The prevalence of hypertension (44.4\%) was maximum followed by high blood sugar (25.2\%) which is very alarming and need corrective action on the war footing. On the other hand hypercholesterolemia is found 
only $5.4 \%$ above the age of 30 years which is also astonishing as high cholesterol is consider to be main cause of coronary heart disease. Further studies are required to break this myth.

\section{Recommendation}

It is high time to accelerate the implementation of NPCDCS (NATIONAL PROGRAMME FOR PREVENTION AND CONTROL OF CANCER, DIABETES, CARDIOVASCULAR DISEASE AND STROKE) programme into the whole country as well as the screening of the population above the age of 30 years by STEPS approach to identify the coronary heart disease risk factors as well as to treat and prevent these so that the overall burden of coronary heart disease can be minimized.

\section{References}

[1]. K Parks, Text Book of Social and Preventive Medicine, K. Park, 23rd Edition, Jabalpur, India: M/S Banarsidas Bhanot Publishers; 2015.p.364-367.

[2]. Murray C, Lopez A. The Global Burden of Disease. Cambridge, Harvard University Press, 1996.

[3]. Global Status Report on Non-communicable disease 2014. World Health Organization, Geneva 2014.

[4]. Who.int. WHO | Disease and injury country estimates [Internet]. 2015 Available from: http://www.who.int/healthinfo/ global_burden_disease/estimates_country/en/

[5]. Vellakkal S, Subramanian S, Millett C, Basu S, Stuckler D, et-al. (2013) Socioeconomic Inequalities in Non-Communicable Diseases Prevalence in India: Disparities between Self-Reported Diagnoses and Standardized Measures PlosOne 8(7): e68219. doi: 10.1371/journal.pone.0068219.

[6]. Gupta R, Joshi PP, Mohan V, Reddy KS, Yusuf S: Epidemiology and causation

a. $\quad$ of coronary heart disease and stroke in India. Heart 2008,94:16-26.

[7]. Prabhakaran D, Yusuf S, Mehta S, Pogue J, Avezum A, Budaj A, et al. Two year outcomes in patients admitted with non-ST elevation acute coronary syndrome: results of the OASIS registry 1 and 2. Indian Heart J 2005;57:217-25.

[8]. Garg A, Anand T, Sharma U, Kishore J, Chakraborty M, Ray P et al. Prevalence of risk factors for chronic non-communicable diseases using who steps approach in an adult population in Delhi. J Fam Med Primary Care. 2014;3(2):112.

[9]. Sekhri T, Kanwar R, Wilfred R, Chugh P, Chhillar M, Aggarwal R et al. Prevalence of risk factors for coronary artery disease in an urban Indian population. BMJ Open. 2014;4(12):e005346-e005346.

[10]. Singh A, Shenoy S, Sandhu JS. Prevalence of type 2 diabetes mellitus among urban sikh population of Amritsar. Indian J Community Med. 2016:41(4): 263-267. Available from: http://www.ijcm.org.in/text.asp?2016/41/4/263/193338

[11]. Reddy K. Methods for establishing a surveillance system for cardiovascular diseases in Indian industrial populations. Bulletin of the World Health Organization. 2006;84(6):461-469.

[12]. Gupta R, Sharma K, Gupta A, Agarwal A, Mohan I, Gupta V et al. Persistent High Prevalence of Cardiovascular Risk Factors in the Urban Middle Class in India: Jaipur Heart Watch-5. J Assoc Physicians India. 2012;60:11-6.

[13]. Gupta R, Deedwania P, Sharma K, Gupta A, Guptha S, Achari V et al. Association of Educational, Occupational and Socioeconomic Status with Cardiovascular Risk Factors in Asian Indians: A Cross-Sectional Study. PLoS ONE. 2012;7(8):e44098.

[14]. Prabhakaran D, Shah P, Chaturvedi V, Ramakrishnan L, Manhapra A, Reddy KS. Cardiovascular risk factors prevalence among men in a large industry of northern India. Natl Med J India 2005;18:59-65.

[15]. Mohan V, Deepa M, Farooq S, Prabhakaran D, Reddy K. Surveillance for risk factors of cardiovascular disease among an industrial population in southern India. Natl Med J India 2008;21:8-13.

[16]. Sugathan T, Soman C, Sankaranarayanan K. Behavioural risk factors for non-communicable diseases among adults in Kerala, India. Indian J Med Res. 2008;127(6):555-63.

[17]. Mishra P, Mini G, Thankappan K. Risk factor profile for non-communicable diseases among Missing tribes in Assam, India: Results from a WHO STEPs survey. Indian J Med Res. 2014;140(3):370-78.

[18]. Aroor B, Trivedi A, Jain S. Prevalence of risk factors of non-communicable diseases in a district of Gujarat, India. J Health PopulNutr 2013;31:78-8 